\title{
Biology and control of the tenlined June beetle in almonds
}

\author{
Robert A. Van Steenwyk Donald Rough $\square$ Paul S. Verdegaal
}

\section{The tenlined June beetle has one generation every two years. Most larvae are in the top 14 inches of soil, and female adults apparently do not fly. Diazinon granules ap- plied to the soil suppress larval populations.}

In California, considerable economic damage to almond, cherry, prune, and apple orchards can occasionally be caused by the feeding of the tenlined June beetle larva, Polyphylla decemlineata (Say). Control of the beetle in heavily infested orchards requires that the infested trees be removed and the soil fumigated. This procedure is extremely expensive and destructive, and removes the orchard from production for a number of years. A study was conducted from 1985 through 1988 to develop a more complete understanding of the beetle's biology and to develop control procedures that would reduce or eliminate the larval population without orchard removal.

\section{Methods and materials}

All studies were conducted in a 22-year-old commercial almond orchard of 'Nonpareil' and 'Merced' cultivars on Lovell root stock at Manteca, California. Trees were planted on a 27-foot tree, 27-foot row spacing in sandy soil ( $90.4 \%$ sand, $5.0 \%$ silt, $4.0 \%$ clay, and $0.6 \%$ organic matter), with a $\mathrm{pH}$ of 6.5 and electrical conductivity (EC) of 0.32 . The orchard was sprinkler-irrigated and naturally infested with the tenlined June beetle.

Larval soil profiles. The larval population was monitored approximately once a month from April 1986 through October 1987. Monitoring consisted of collecting a minimum of 50 larvae with a minimum of three soil profile samples. Each soil sample was approximately 3 feet long by 1 foot wide. Soil was removed at 2 -inch intervals down to a depth of 2 feet. The soil at each 2inch interval was visually inspected for larvae in the field. The head capsule of each larva at each depth interval was measured at its widest point to determine the instar.
Adult emergence and seasonal and nocturnal flight. Adult emergence from the soil was monitored weekly from May 28 though October 14, 1985, and from May 13 through October 2, 1986, in eight pyramidshaped emergence cages (9-square-foot base, 3-foot height). Seasonal adult flight activity was monitored from June 11 through August 30,1986, with three light traps. The lights were operated continuously, and once a week the captured beetles were counted and their sex determined. Nocturnal adult flight was monitored on four nights (July 29, August 5, August 26, and September 3, 1987); three light traps were monitored every half hour from $1 / 2$ hour before sunset through 2 a.m. The traps were inspected again at $8 \mathrm{a}$.m. Temperature at each collection and time of sunset were recorded.

Mating and oviposition. Adult mating behavior was observed on August 26 and September 3, 1987, from approximately 1 hour before to 1 hour after sunset. We noted the time of copulation and the female's behavior after copulation for eight mating pairs for the two nights. Immediately after the mated females re-entered the soil, seven were collected (one escaped) and placed in 3-liter containers with moist orchard soil, in which they were held in the laboratory.

The females were allowed to oviposit for three weeks. The eggs were then removed from the soil and placed in Petri dishes with moist filter paper. The eggs were observed daily for hatch. At hatch, head-capsule width for the first instars was measured at the widest point.

Insecticide evaluation. Control of the tenlined June beetle with granular insecticides was evaluated in three studies conducted in 1985,1986, and 1988. The 1985 and 1986 studies replicated five treatments five times in a completely randomized design. The treatments were diazinon ( $14 \mathrm{G}$ at 5 and $10 \mathrm{lb}$ active ingredient $[\mathrm{AI}]$ per acre), carbofuran (10 G at 5 and $10 \mathrm{lb}$ AI per acre), and an untreated control. Each replicate consisted of a single tree. The insecticide granules were applied evenly over 730 square

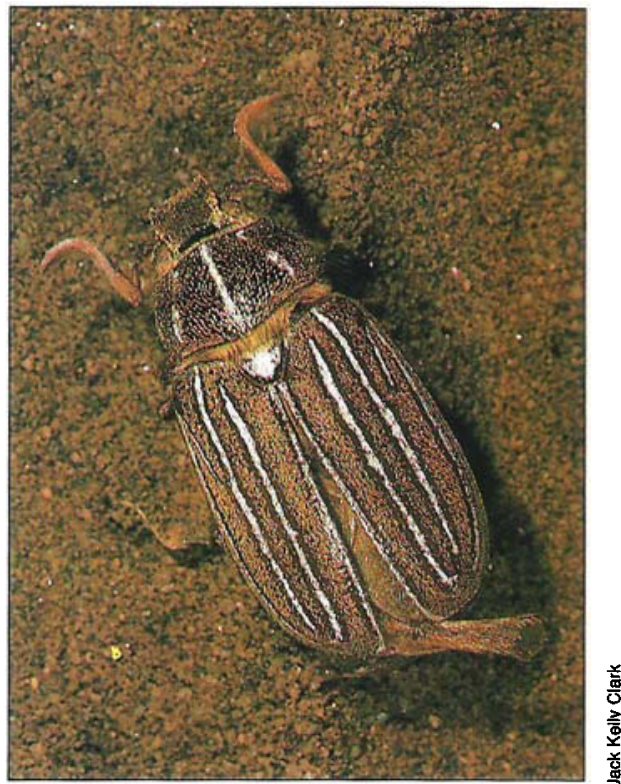

The adult tenlined June beetle lays its eggs in the orchard soil in late summer and early autumn. The hatching larvae subsequently cause damage to several fruit and nut crops.

feet around each tree on November 7, 1985 (trial 1), and April 25, 1986 (trial 2).

The insecticides were disked and watered in with about 2 inches of sprinklerapplied water on the day of application. Control was evaluated by counting all larvae in four 1-square-foot, 2-foot-deep soil samples taken around each tree on January 8, 1986, and April 25, 1986 (trial 1), and on June 12, 1986 (trial 2).

In 1988, two treatments were replicated four times. The treatments were diazinon (14 G at 2.8 lb Al per acre) and an untreated control. The replicates in the diazinon treatments were six rows wide by 20 trees long. In the untreated control, the replicates were three rows wide by 20 trees long.

The insecticide granules were applied evenly under the trees' dripline on May 27 and October 11 . The insecticides were then disked and watered in with about 2 inches of sprinkler-applied water on the day of application. We evaluated the effectiveness of control by counting all larvae in eight 1cubic-foot soil samples taken around four center trees for each replicate on April 26 (pretreatment), July 15, and November 28.

\section{Results and discussion}

Larval soil profiles. The monthly soil profile samples produced more than 1,300 larvae with approximately equal numbers of each instar over the $1 / 2$-year sampling period. The frequency distribution of head capsule widths from all larvae collected in the samples indicates three instars. The mean (X), standard deviation (SD), range, and number of observations $(\mathrm{N})$ were as follows: first instar $X=2.9 \mathrm{~mm}, \mathrm{SD}=0.11$ $\mathrm{mm}$, range $=2.4$ to $3.2 \mathrm{~mm}, \mathrm{~N}=492$; second 


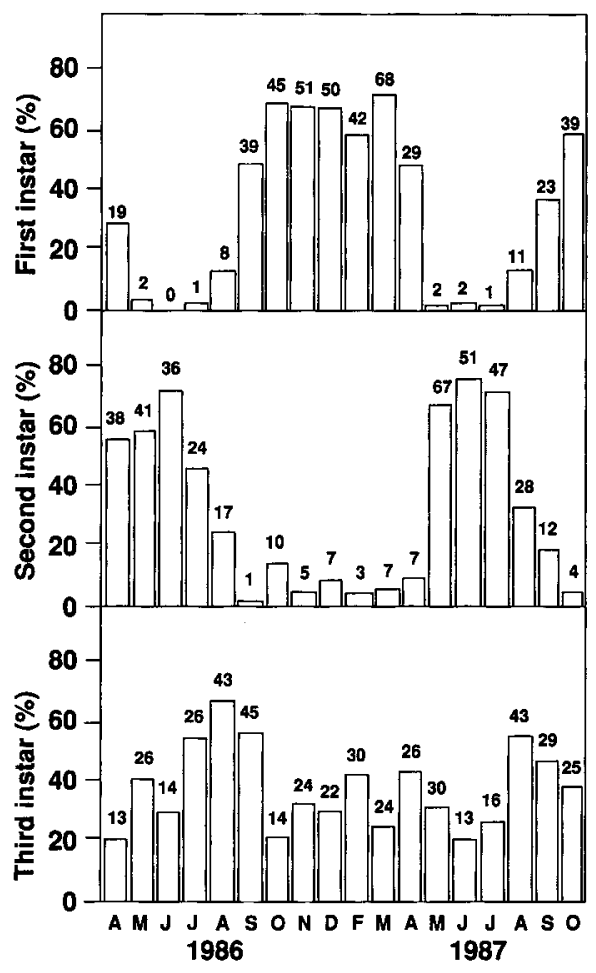

Fig. 1. Percentage and number of larvae in various instars, without regard to soil depth at collection, in monthly soil profile samples taken at Manteca, California.

instar $X=4.8 \mathrm{~mm}, \mathrm{SD}=0.27$, range $=4.0$ to $5.5 \mathrm{~mm}, \mathrm{~N}=439$; and third instar $X=7.2$ $\mathrm{mm}, \mathrm{SD}=0.40 \mathrm{~mm}$, range $=6.0$ to $8.7 \mathrm{~mm}$, $\mathrm{N}=535$.

Very few first instars were collected per sample from May through July (fig. 1). By August, the first instars had increased, and they remained high during the winter. These larvae overwintered until March. The second instars reached a peak population by June and then started molting into third instars. Few second instars overwintered. The third instars did not show a similar cyclic pattern. They increased from June through August as second instars molted into third instars. These third instars then overwintered. The following summer, the overwintered third instars pupated and emerged as adults. These data indicate that the tenlined June beetle has one generation every 2 years in California.

All three instars were found throughout the soil profile, with most occurring between 2 and 14 inches deep. The larvae were always associated with almond roots, and because of the sandy soil type, the majority of roots were located in the 2 - to 14 -inch soil zone. When individual trees were removed, we could observe larval feeding on roots 5 feet deep. It appears that larvae may follow the roots to any depth. As a percentage of total larvae per depth, the first instars tended to stay closer to the soil surface,

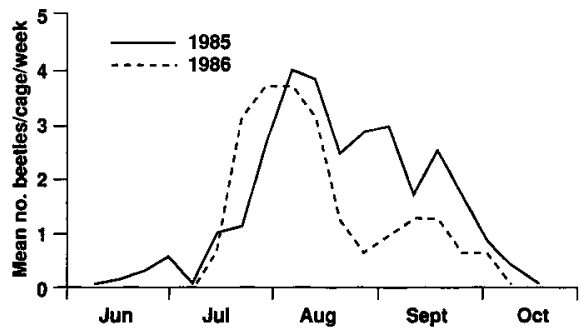

Fig. 2. Seasonal emergence of tenlined June beetle adults in 1985 and 1986 (multiplied by 5) at Manteca, California.

whereas numbers of third instars tended to increase with soil depth. The percentage of second instars did not show a trend with depth.

Adult emergence and seasonal and nocturnal flight. In 1985, adult emergence began in mid-June and continued until midOctober with peak emergence in early August (fig. 2). In 1986, adult emergence began in mid-July and continued to early October with peak emergence again in early August (fig. 2). The number of beetles collected in 1986 (32) was much lower than in 1985 (235), and peak emergence occurred about one week earlier in 1986.

A possible explanation for the large difference in numbers of adults emerging in 1985 and 1986 is that because the beetles take 2 years to complete a generation, the numbers of ovipositing females may not have been equal in 1983 and 1984. There could also have been differential larval mortality between the 1985 and 1986 populations. Seasonal adult flight as measured by light traps in 1986 showed a pattern comparable to that of adult emergence from the soil (fig. 3). The flight began in mid-June, although we captured few beetles in June, and continued to September with peak flight in mid-August. Of the more than 15,000 beetles collected in the light traps, all were males. Apparently, females either do not fly or are not attracted to light traps.

The tenlined June beetle's period of greatest flight activity begins shortly after sunset and continues until midnight or 1:30 a.m. Flight activity seems to be influenced by temperature, with longer activity periods on warm nights and shorter periods on cooler nights. Adult flight began about $1 / 2$ hour before sunset, although no beetles were captured in the light traps until about an hour later. No beetles were captured in the light traps the following morning, so there appears to be no early morning flight. The majority of adult beetles flew close to the ground, at heights of $1^{1 / 2} 2$ to 6 feet and in irregular patterns.

Mating and oviposition. Mating took place as the female emerged from the soil, usually at the emergence hole or a very short distance (1 inch) from the hole. Females probably emitted sex pheromones

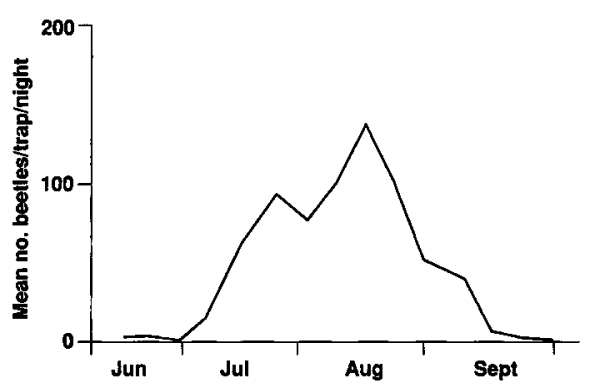

Fig. 3. Seasonal flight activity of tenlined June beetle adults in 1986 at Manteca, California.

before exiting their emergence holes, since males were observed at the emergence holes in advance of female emergence. The time of copulation for eight mating pairs was $2.0 \pm 0.78$ minutes, with a range of 1.25 to 3.75 minutes. After copulation, the female either re-entered her emergence hole or, if she had been moved off her emergence hole by two males attempting to mate, she moved a short distance (maximum distance observed was 6 feet) before re-entering the soil. At no time did we observe female flight.

Seven of the eight mated females were placed in 3-liter containers with orchard soil. The seven females deposited a total of 82 creamy white eggs. These eggs hatched 25 to 29 days after the females had been placed in the containers. On the day of hatch, the average head-capsule width of these 82 first instars (100\% hatch) did not differ from first instars observed in the soil profile samples.

Insecticide evaluation. In the 1985 and 1986 trials, we achieved a significant reduc-

TABLE 1. Effect of diazinon and carbofuran granules for control of tenlined June beetle larvae, measured in 1986, Manteca, California

\begin{tabular}{|c|c|c|c|c|}
\hline \multirow[b]{3}{*}{ Treatment $\ddagger$} & \multirow[b]{3}{*}{$\begin{array}{l}\text { Pounds Al } \\
\text { per acre }\end{array}$} & \multicolumn{3}{|c|}{$\begin{array}{c}\text { Mean larvae per } \\
\text { sq ft sample } t\end{array}$} \\
\hline & & Trial 1 & \multicolumn{2}{|c|}{ Trial 2} \\
\hline & & $1 / 8$ & $4 / 25$ & $6 / 12$ \\
\hline Carbofuran $10 \mathrm{G}$ & 10.0 & 1.4 & $0.1 \mathrm{a}$ & $0.10 \mathrm{a}$ \\
\hline Carbofuran $10 \mathrm{G}$ & 5.0 & 1.6 & $0.7 a b$ & $0.5 a b$ \\
\hline Diazinon $14 \mathrm{G}$ & 10.0 & 1.0 & $0.9 a b$ & $0.7 a b$ \\
\hline Diazinon $14 \mathrm{G}$ & 5.0 & 1.3 & \multirow{2}{*}{$\begin{array}{l}0.7 a b \\
1.30 b\end{array}$} & $0.2 a b$ \\
\hline Untreated control & $1 \quad-$ & 1.2 & & $1.2 \mathrm{~b}$ \\
\hline \multicolumn{5}{|c|}{$\begin{array}{l}\text { "Means within columns followed by the same letter are } \\
\text { not significantly different }(P=0.1 \text {; DMRT). } \\
\text { tSoil samples were } 1 \mathrm{ft} \text { square by } 2 \mathrm{ft} \text { deep. } \\
\text { ‡Treatments applied on } 11 / 7 / 85 \text { (trial } 1 \text { ) and } 4 / 25 / 86 \\
\text { (trial 2). }\end{array}$} \\
\hline \multicolumn{5}{|c|}{$\begin{array}{l}\text { TABLE 2. Effect of diazinon granules for control of } \\
\text { tenlined June beetle larvae in 1988, } \\
\text { Manteca, California }\end{array}$} \\
\hline \multirow[b]{2}{*}{ Treatment $\dagger$} & & & \multicolumn{2}{|c|}{$\begin{array}{l}\text { Mean larvae per } \\
\text { cu ft sample* }\end{array}$} \\
\hline & $\begin{array}{l}\text { Pounds } \\
\text { per acre }\end{array}$ & $4 / 4$ & $7 / 15$ & $11 / 28$ \\
\hline Diazinon $14 \mathrm{G}$ & 2.8 & $3.4 a$ & $0.1 \mathrm{a}$ & $0.6 a$ \\
\hline Untreated control & - & $3.0 a$ & $0.8 b$ & $2.3 b$ \\
\hline
\end{tabular}


tion of tenlined June beetle larvae by using $10 \mathrm{lb}$ AI per acre of $10 \mathrm{G}$ carbofuran, and we observed suppression with $5.0 \mathrm{lb}$ AI per acre of $10 \mathrm{G}$ carbofuran and 10 and $5 \mathrm{lb} \mathrm{AI}$ per acre of $14 \mathrm{G}$ diazinon (table 1 ). In trial 1 , when insecticides were applied on November 7,1985 , the first evaluation on January 8 , 1986 , showed no significant difference between treatments. However, when we reevaluated the trial on April 25, 1986, we observed significant mortality. Thus, the larvae must be feeding actively, which they do when soil temperatures warm in the spring, in order for the insecticides to be effective. In trial 2, when insecticides were applied on April 25, 1986, significant mortality was observed 7 weeks after treatment. In the 1988 trial, significant reduction of tenlined June beetle larvae was achieved with $2.8 \mathrm{lb}$ AI per acre of diazinon $14 \mathrm{G}$ when applied commercially in large plots.

These studies indicate that suppression but not complete control of tenlined June beetle larvae can be achieved with granular applications of diazinon, which is registered for use in almond in California. Carbofuran, if it becomes registered for this use in the future, will be an alternate insecticide.

\section{Conclusion}

From our studies, the tenlined June beetle appears to have limited dispersal because mated females do not move far, and the beetle has only one generation every 2 years. Thus, infestations will spread very slowly. Controlling the adult beetles with foliar insecticides does seems unlikely because of the prolonged adult male emergence and female behavior after mating. The most suitable stage for control would be larval, with application of soil insecticides in September. This timing would correspond to egg hatch, and newly emerged first instars would be most susceptible to control. A second application would come in May, before third instar pupation.

These two application timings would occur when the larvae are actively feeding in warm soil. Controlling the larvae with soil insecticides would permit suppression of the population without costly and destructive tree removal and fumigation.

Robert A. Van Steenwyk is Extension Entomologist, Department of Entomological Sciences, University of California, Berkeley; Donald Rough is Farm Advisor (retired) and Paul S. Verdegaal is Farm Advisor, Cooperative Extension, San Joaquin County.

The authors gratefully acknowledge the assistance of B. A. Barr, L. W. Barclay, and C. F. Fouche, Cooperative Extension, University of California, Berkeley, and R. Freeman and D.M. Havens, Cooperative Extension, Stockton, for their help in this study. They also gratefully acknowledge Van Dyken Farms' provision of a study site. This research was supported in part by the Almond Board of California.

\title{
Melaleuca alternifolia: new crop for California?
}

\author{
Roy M.Sachs a Choong I. Lee $\square$ Sue A.Cartwright $\square$ Michael S. Reid \\ Colin Smith
}

\section{Researchers say tea trees can be grown successfully and with profitable oil yields in California's Central Valley. Based on an analy- sis of seedlings from one seed source, the yield from a seedling plantation would be about half that of a clonal plantation derived from the best seedlings.}

Foliage of Melaleuca alternifolia [Cheel], a woody perennial commonly known as the tea tree and native to northern New South Wales, Australia, contains approximately 1 to $2 \%$ (by fresh weight) essential oil. This oil, because of its demonstrated antibacterial and antifungal activity, has commercial value in the treatment of skin lesions and is used in the manufacture of shampoos and other health-related products. The market for tea tree oil in the United States is increasing, and demand currently exceeds supply. Prices for the oil imported from Australia exceed $\$ 10$ per pound. Research on the agronomic and horticultural characteristics of the crop was considered an essential preliminary step to determining its economic potential in California.

Plant materials. We sowed seeds of $M$. alternifolia densely in rows spaced $1 \mathrm{~cm}$ apart in a flat of a fine-grained sand. The surface was kept moist by misting at 2.5minute intervals during daylight hours. Flats were maintained at $75^{\circ} \mathrm{F}$. The germination rates of three seed lots were between 10 and $20 \%$ over several weeks. Emergence in the flats occurred at 2 weeks. About 6 weeks after emergence, the most vigorous seedlings were transplanted to peat pots in a peat-sand mixture, which were then maintained in a greenhouse at $75^{\circ} \mathrm{F}$ during the day and $65^{\circ} \mathrm{F}$ during the night for another 5 to 6 weeks. Plants were then moved to a lath house for a week of hardening before field planting.

Plantation establishment and performance. Using about 250 of the most vigorous seedlings, we established a $0.2-$ acre plantation, with plants spaced on 2.5 - to 3-foot centers under drip irrigation (one emitter per seedling) in April 1986 at UC Davis. One hundred pounds of elemental nitrogen was applied as ammonium sulfate in the spring of the second year of cultivation. We observed considerable variation in the vigor of seedlings within a few months of planting, and many seedlings became

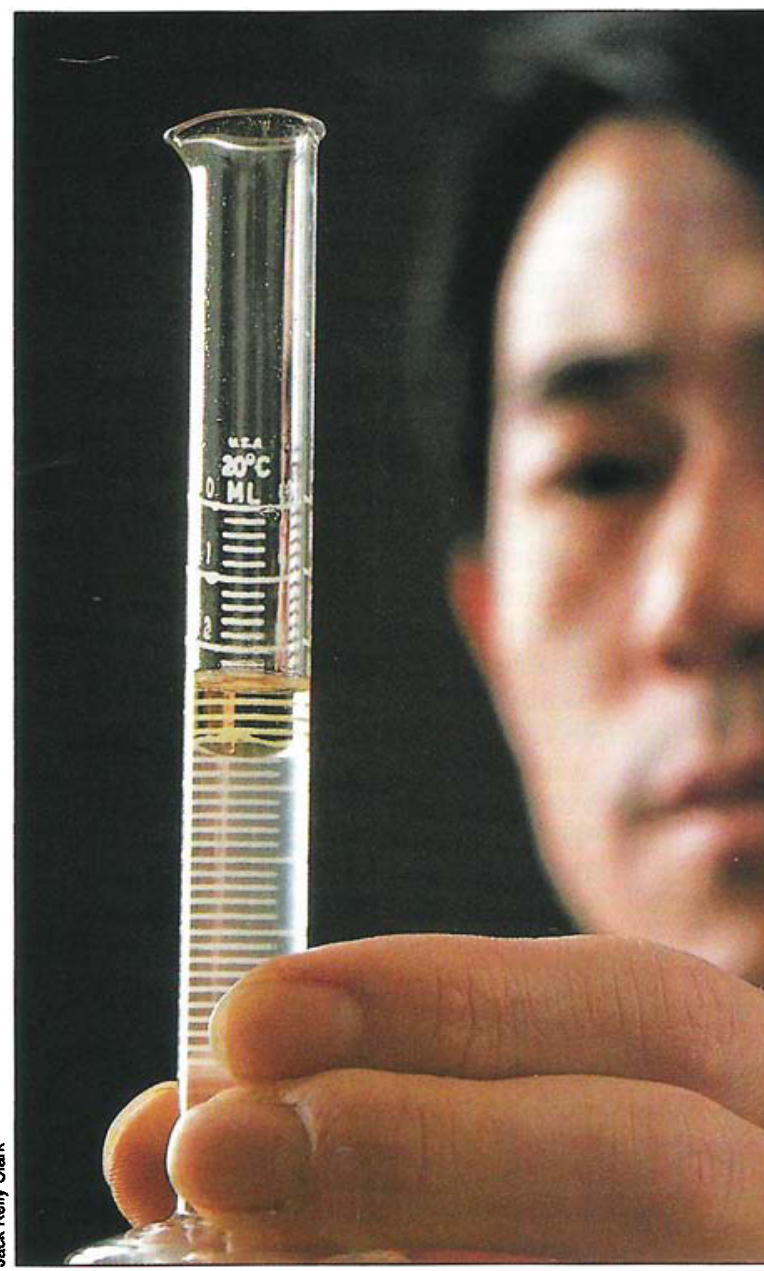

Tea tree oil floats on water in this graduated test tube. The antibacterial and antifungal properties of this oil make the tea tree a valuable crop for medical and hygene applications. 